\title{
Pedestrians' perception of environmental stimuli through field surveys: focus on particulate pollution
}

\author{
Marialena Nikolopoulou ${ }^{1}$, Jan Kleissl $1^{2}$,P.F. Linden ${ }^{2}$ and Spyros Lykoudis ${ }^{3}$
}

1. University of Bath, Department of Architecture and Civil Engineering, Bath BA2 7AY, UK, Tel.: +44 1225 386296, Fax: +44 1225 386908, email: mhnikol@hotmail.com

2. University of California San Diego, Department of Mechanical \& Aerospace Engineering, La Jolla, CA 92093-0411, USA, email: jkleiss1@ucsd.edu, p.f.linden@damtp.cam.ac.uk

3. National Observatory of Athens, Institute of Environmental Research \& Sustainable Development, I. Metaxa and V. Pavlou, Penteli 152 36, Greece, email: slykoud@meteo.noa.gr

\begin{abstract}
The connection between perception of individual exposure to different environmental stimuli; microclimate, noise and especially particulate matter (PM) was examined. Microclimate, noise and PM were monitored during field surveys with 260 questionnaire-guided interviews at a road construction site and a traffic site on the UC San Diego campus. The overall comfort was determined primarily by the thermal environment. The air quality was considered to be poor by $42 \%$ of the interviewees at the construction site, which was burdened with higher PM counts and sound levels. Overall, higher PM concentrations were correlated with perception of poor air quality. Similarity between the overall air quality and how dusty it feels suggests that visual clues of PM, such as dust, affect the perception of air quality and pollution. The effect of medical or smoking history on the perceived air quality was also examined. People with a medical history of hay fever voted more frequently for poor air quality conditions than those without, whereas current smokers were the least sensitive to ambient air quality conditions. Through the exposure-response relationships between the various perception votes and PM, it was possible to predict perceived air cleanness using the PM count. Understanding the human assessment of environmental stimuli could inform the design and development of urban spaces, in relation to the allocation of uses and activities, along with air quality management schemes.
\end{abstract}

Keywords: perception, air quality, thermal environment, noise, urban design

\section{Introduction}

Urban populations are vulnerable, as a result of the Urban Heat Island, where temperatures in built areas are higher than the surrounding countryside, and poor air quality due to enhanced local emissions (Daniels et al., 2000; Yaghoobian et al. 2010). This vulnerability to chronic exposure will increase further under global warming, as increased temperatures increase heat stress and are often associated with higher pollution concentrations (Sarrat et al., 2006).

In the context of sustainable urban environments, there is increased interest on the provision of open spaces and environmental quality. A successful network of external public spaces promoting outdoor living can play an important role in cooling cities. It can also prevent people from withdrawing to air-conditioned indoor spaces, further burdening the environment under increased air temperatures due to urbanization and climate change. Open spaces can be even more beneficial in neighbourhoods with poor socio-economic status. Increased outdoor presence enhances security and increases physical activity thus reducing the burden of chronic diseases. Other benefits include enabling the increased use of greener modes of transport, such as cycling and walking.

To improve the environmental quality and design of open spaces, it is critical to evaluate individuals' perception of environmental conditions, in particular microclimate, noise and air quality. Such knowledge also can be used to induce environmentally sustainable behaviour. Understanding the human assessment of air quality will allow the development of targeted outreach campaigns by local authorities and policy makers to protect the population from such exposure, as recent studies found that air quality advisories for the public were not effective in changing individuals' behaviour, even in 
severe air quality episodes. Behaviour change was predominantly motivated by perception of the environmental conditions and not the advisory system (Semenza et al., 2008).

This article seeks to improve our understanding of the perception of different environmental stimuli, focusing on the sensory awareness of individuals' exposure to different levels of resulting environmental quality, by monitoring microclimate, noise, and especially particulate matter (PM) in a focused case study. PM (i.e. small particles) is of great concern because it can remain airborne for days (Park et al., 2006; Sapkota et al., 2005), contains toxic substances that accumulate over the particle lifetime (Moffet et al., 2008) and enters the human lungs (Harrison, 2004).

Microclimatic conditions are now increasingly accepted as a critical parameter for the use of open spaces in the urban environment, although the responses to the microclimate may be unconscious (Nikolopoulou et al., 2001). This study also highlighted that theoretical thermoregulatory models do not accurately reflect the perception and evaluation of outdoor comfort conditions. Consequently, various field surveys have been conducted to investigate people's perception of microclimatic parameters and the resulting thermal comfort conditions. The RUROS study was conducted with surveys in different European cities in 2001-2002 (Centre for Renewable Energy Sources, 2002). Local microclimatic monitoring was combined with the evaluation of these conditions by users of open spaces, leading to a large database of nearly 10,000 interviews. This comparison of objective and subjective data shed light on the understanding of outdoor thermal comfort through perception (Nikolopoulou and Lykoudis, 2006) and even suggested relationships between meteorological parameters and thermal sensation and comfort, based on empirical data (Nikolopoulou et al., 2004). RUROS also evaluated the acoustic environment and psychological parameters in perceiving soundscape (Yang and Kang, 2005). They found that although subjective evaluation of the sound levels were correlated with the mean equivalent sound pressure levels, considerable differences occurred with the acoustic comfort evaluation. The importance of personal parameters, activities, perceptions, and other non-acoustic factors for the evaluation of acoustic comfort has since been confirmed by further studies (Szeremeta et al., 2009; Kang and Zhang 2010).

In the field of air quality, identifying relationships between perceived and actual levels of pollutants has not been possible (Brody et al., 2004). Due to the serious health implications of different air pollutants most of the work on perception has focused on the perceived risks and epidemiological studies (Oglesby, et al., 2000; Rotko et al., 2002; Klæboe et al., 2008, Llop et al., 2008; Badland and Duncan, 2009). While public perception studies have been dating back to the 1960s (Craik and Zube, 1976; Brody et al., 2004), only recently has empirical research started to examine the local level (Brody et al., 2004). Even in these cases, the data are usually stratified by neighbourhood and not measured or assessed at the local pedestrian level. This assessment at pedestrian level is important as recent studies revealed that there are large variations between the air quality levels at fixed monitoring stations and at the local scale, or even at different sides of the road (Kaur et al., 2005)

Most studies on perception of air pollution have been carried out through social and public opinion surveys, which focused almost exclusively on the awareness or level of concern about air pollution, with a few studies also investigating behavioural impacts or the psychological consequences of air pollution (Howel et al., 2003). A recent review of the air pollution perception literature (Bickerstaff and Walker, 2001) showed that publicity about air pollution has been an important factor in influencing public awareness of air pollution. Thus it was not possible to identify whether people actually sensed polluted air in their environment, or whether their perception was biased by media coverage. Assessing the ability of people to detect the existence of polluted air in their environment is further complicated by the interference of other environmental parameters affecting the overall comfort of the individual.

Recent studies on the local scale have provided information on place-specific conditions and evaluated how the location and its surroundings are important in the experience of air pollution (Day, 2007; Brody et al., 2004; Bonnes et al., 2007). Arguing that the psychological effects of air pollution may often be more important to well-being than the biophysical effects, the EXPOLIS project also linked annoyance with exposure to air pollution from vehicular traffic (PM2.5, PM10 and $\mathrm{NO}_{2}$ ) at different cities across Europe (Rotko et al., 2002; Amudsen et al., 2008; Klæboe et al., 2008).

Also, studies evaluating indoor environmental conditions in climate chambers and offices have shown that perception of air quality is significantly influenced by temperature and humidity (Fang et al., 2004). Wargocki (2004) agrees that the combined effect of olfactory, chemical and 
thermal sense affects the perception of air quality in the indoor environment. As the outdoor context offers enormous variability in microclimatic and air quality conditions, it could then be expected that perception of air pollution varies under different weather conditions (e.g. calm wind conditions, temperature inversions, heat waves, large solar irradiance resulting in photochemical smog, etc.).

This paper investigates the individual perception of exposure to different environmental stimuli, especially PM, at the local scale. The research framework and data collection are described in section 2 and the conditions of thermal environment, noise, and PM are summarized in section 3 . In section 4, we examine the perception of these stimuli separately by type. Potential sensitivity to PM is also examined via the effect of medical and smoking history on the perceived air quality. The development of exposure and response relationships, based on sensory awareness, is examined in section 5. It is important to stress that this is a focused study, aiming to test the validity of the overall concept which could then lead to large-scale empirical studies. Such studies could investigate threshold levels at which different air pollutants can be perceived, sensory adaptation and habituation, as well as confounding effects of different forms of air/noise pollution and microclimate.

Understanding the human assessment of environmental stimuli could inform the development of urban spaces, in relation to the allocation of uses and activities, as well as evaluating physical interventions to improve environmental quality. At a different level, such knowledge could indirectly inform air quality management schemes by addressing the public's interaction with the environment and motivation for change.

\section{Research framework}

The University of Bath, UK, and the University of California, San Diego (UCSD, USA) collaborated in a project to evaluate the individual perception of exposure to different environmental stimuli and different concentrations of particulate matter (PM). Since westerly (onshore) winds persist for most of the year, significant PM concentrations in coastal San Diego are only expected near construction sites or during forest fire events (County of San Diego Air Pollution Control District, 2007).

The UCSD campus was used as a case study for several reasons. There are various on-going construction projects and hence elevated PM levels could be studied. Also, UCSD has established a unique network of stations to monitor environmental conditions on campus for the Decision Making using Real time Observations for Environmental Systems (DEMROES) project (Dominguez et al., 2007) that provided the microclimatic information and measurement infrastructure necessary for this work. Furthermore, as the campus is reminiscent of suburban environments, perceptions are not subject to the urban vs. rural dichotomy that could lead to location being the parameter controlling perception, rather than air quality levels themselves (Brody et al., 2004).

The field surveys involved questionnaire-guided interviews with the users of two sites on the UCSD campus (near $32.88^{\circ} \mathrm{N}, 117.24^{\circ} \mathrm{W}$ ), one a key node for vehicular traffic and public transportation (TS) and the other a construction site (CS), where road surfacing work was conducted, bordering a park on one side and built up areas on the other. The two sites were about $750 \mathrm{~m}$ apart along a NNW-SSE axis, about 1500m east of the Pacific Ocean (Fig. 1).

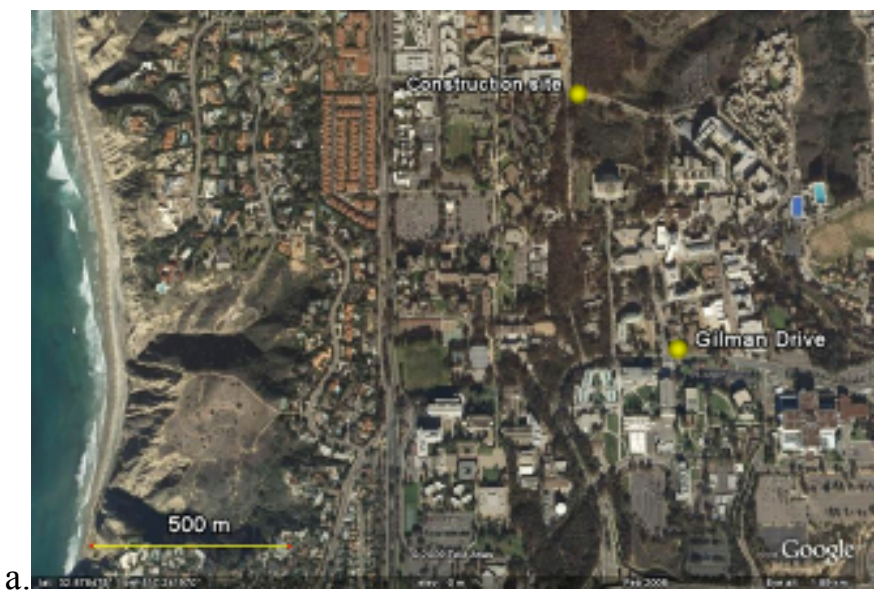



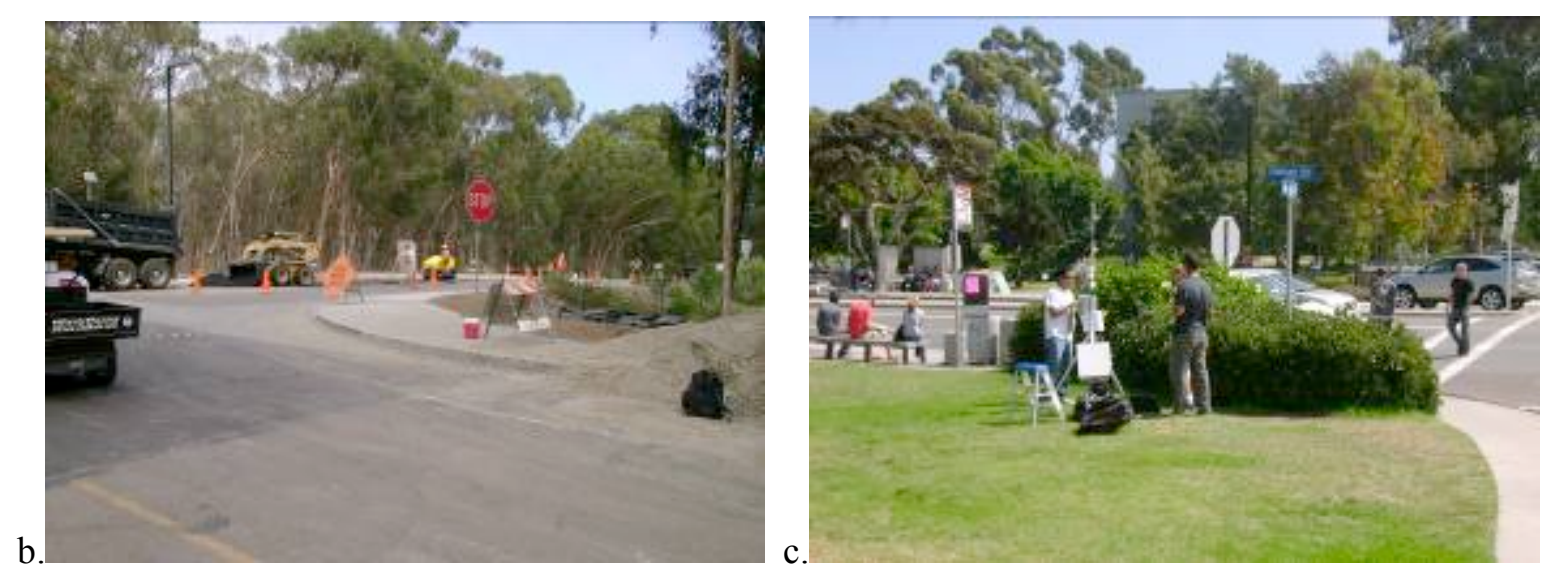

Fig. 1: (a) Overview of the survey sites (adapted from Google Earth), (b) Gilman shuttle stop TS with the DEMROES station visible in the centre, (c) Construction site CS.

The surveys were conducted in summer 2008 by undergraduate students at UCSD who were trained prior to the project in survey techniques and use of questionnaires. Concurrent highly timeresolved environmental monitoring was taking place locally, in order to record the microclimatic, noise and air quality parameters the interviewees were experiencing. To this effect, an enhanced mobile DEMROES station, mounted on a $2 \mathrm{~m}$ high tripod, was installed temporarily at the survey sites. It was equipped with an Extech 407740 Type 2 sound level meter (at $1.5 \mathrm{~m}$ above ground level), a Davis Instruments anemometer and wind vane at $1.9 \mathrm{~m}$, a Humirel HTM2500 temperature and relative humidity probe at $1.8 \mathrm{~m}$, and a Licor SZ200 pyranometer at $2 \mathrm{~m}$.

A Shinyei PPD20V particle counter sensitive to particles with a diameter larger than $1 \mu \mathrm{m}$ was used to determine the number concentration of PM in particles per litre. PM emissions from traffic combustion are smaller than $0.5 \mu \mathrm{m}$ and cannot be detected with this device. Based on a detailed chemical characterization of particulate matter at a nearby site (Toner et al., 2008) we expect the majority of the particles in the $>1 \mu \mathrm{m}$ range to be sea salt and local dust from the wind shear created by vehicular traffic and construction. Since international health standards and PM measurements are usually reported in $\mu \mathrm{gm}^{-3}$ a conversion factor was needed to allow better intercomparison of the reported PM concentrations. Given that the sensor used is able to identify particles between $1 \mu \mathrm{m}$ and $10 \mu \mathrm{m}$ and assuming a typical PM size distribution, the average aerodynamic diameter would be around $3 \mu \mathrm{m}$ (Seinfeld and Pandis, 1997). Thus, for a typical silicate particle density of $2.2 \mathrm{gcm}^{-3}$ the conversion factor for transforming particle counts per volume air into particle mass per volume air would be equal to $0.028\left(\mu \mathrm{g} \cdot \mathrm{m}^{-3}\right.$ per part/l). This conversion to mass concentration is approximate but does not affect the analysis qualitatively.

Using meteorological and air quality variables recorded every 2 seconds, average meteorological and air quality, and equivalent sound level values were calculated for the exact period when each interview was conducted. The interviews were carried out at a distance of at least $5 \mathrm{~m}$ from the sound level meter, to avoid influencing the noise levels.

The participants in the surveys included students and staff, selected at random, from the areas under investigation. They were asked to answer all the questions with direct reference to the site they were interviewed at and for the specific moment in time; as opposed to their general impression of the area.

As no general evaluation was asked for, this approach should avoid any bias through the "halo effect' where residents in an area are reluctant to recognise poor air quality conditions in their vicinity (Bickerstaff and Walker, 2001; Bickerstaff, 2004).

The questionnaire was developed by merging microclimatic parameters and noise questions similar to the RUROS project (Centre for Renewable Energy Sources, 2002) with air quality questions from studies on indoor climate (Engvall et al., 2004; EPA, 2003; Mendell et al., 2007; Wargocki et al., 1999). Specifically, the questionnaire asked for gender, age, smoking status, perceptions about the thermal and acoustic environment, environmental quality, and health and well-being. The symptoms elicited from the questionnaire included nose blocked, dry nose / throat / mouth / skin; and dry or itchy eyes. Past history with asthma, hay fever and eczema were also taken into account. The interviewees 
were reporting their evaluation of different environmental parameters on a 5-point scale and preference on a 3-point scale, as well as their assessment of their overall comfort state (Table 1).

Table 1: Extract from the questionnaire related to the environmental conditions

How would you describe the wind environment at the moment?

$\begin{array}{cllll}\text { very windy } & \text { windy } & \text { moderate } & \text { a bit calm } & \text { calm } \\ 1 . \square & 2 . \square & 3 . \square & 4 . \square & 5 . \square\end{array}$

Would you prefer it to be?

$\begin{array}{cll}\text { more windy } & \text { no change } & \text { less windy } \\ 1 . \square & \text { 2. } \square & 3 . \square\end{array}$

At the moment, do you find it:
cold
cool
neither cool nor warm
4. $\square$
hot
1. $\square$
2.
3. $\square$
5.

Would you prefer to be:
cooler
1.
no change
2 .
warmer
3.

With regard to overall weather conditions, are you feeling comfortable at the moment?
yes
2. $\square$

What is your opinion of the air at the moment?
very clean
fairly clean
2. $\square$
neither clean nor dusty
3. $\square$
fairly dusty
very dusty
1.
4.
5.

What is your opinion of the overall air quality at the moment? very good fairly good
neither good
1.
2 .
3.
fairly poor
very poor
5.

How would you describe the acoustic environment at the moment?

$\begin{array}{ccclc}\text { very quiet } & \text { fairly quiet } & \text { neither quiet nor noisy } & \text { fairly noisy } & \text { very noisy } \\ 1 . \square & 2 . \square & 3 . \square & 4 . \square & 5 . \square\end{array}$

\section{Environmental and demographic data}

Overall, six days of surveys were carried out in August and September 2008. A total of 260 questionnaires were completed.

Descriptive statistics and histograms were employed to illustrate the interviewees' characteristics, their responses, as well as possible differences between sites or groups of people. Whenever needed chi-squared tests provided significance levels for the observed differences. The relationship between the various perception variables and the implied causative environmental parameters was investigated using Pearson correlation coefficients. All the coefficients reported in the following sections are significant at the 0.05 level or better. The effect of confounding parameters was also investigated using partial correlation coefficients and cross-tabs, as well as chi-squared tests against equiprobability. Finally, ordinal regression based on a logit probability model, was used to quantify the relevance of the various parameters with respect to the reported perception votes. All data analyses were performed with SPSS (SPSS Inc., 2008).

\subsection{Microclimatic data}

Weather conditions in San Diego are strongly affected by proximity to the ocean resulting in a diurnal sea breeze circulation which, in turn, results in a small diurnal temperature range and high humidity (Western Regional Climate Center, 2009). The range of air temperature over the specific measurement periods was small $\left(20.6{ }^{\circ} \mathrm{C}\right.$ to $\left.24.4{ }^{\circ} \mathrm{C}\right)$ with a mean of $23.1{ }^{\circ} \mathrm{C}$. Relative humidity was moderate to high (mean at $79 \%$ ) and also had a narrow range, varying from $71 \%$ to $85 \%$. Although all 
survey days were sunny, the changing solar angle and surrounding obstructions caused global horizontal solar radiation to be more variable. Wind speeds were low, varying between $0.3-3 \mathrm{~ms}^{-1}$, with a mean value of $1.5 \mathrm{~ms}^{-1}$. There was no significant topographical difference between the two sites, as both of them are open and exposed to the wind.

\subsection{Sound level data}

Equivalent sound pressure levels were obtained from the $2 \mathrm{~s}$ measurements (in $\mathrm{db}(\mathrm{A})$ ), by first converting the latter to sound pressures (in $\mathrm{Pa}$ ) that can be averaged arithmetically, and then converting these to sound pressure levels (in $\mathrm{dB}(\mathrm{A})$ ) (Pfafflin and Ziegler, 2006).

Sound pressure levels are higher for the CS (Fig. 2a,b). Although both sites have a minimum sound pressure level around $62 \mathrm{~dB}(\mathrm{~A})$, the maximum value of the $\mathrm{CS}$ is $87.5 \mathrm{~dB}(\mathrm{~A})$, as opposed to $77.1 \mathrm{~dB}(\mathrm{~A})$ for TS. Overall, the acoustic environment is rather poor for both areas, with equivalent sound pressure levels of $78.6 \mathrm{~dB}(\mathrm{~A})$ and $68.9 \mathrm{~dB}(\mathrm{~A})$, for the $\mathrm{CS}$ and TS, respectively. These values represent the noisy activities taking place (construction activities/heavy machinery in the former, high level of vehicular traffic and buses particularly in the latter).
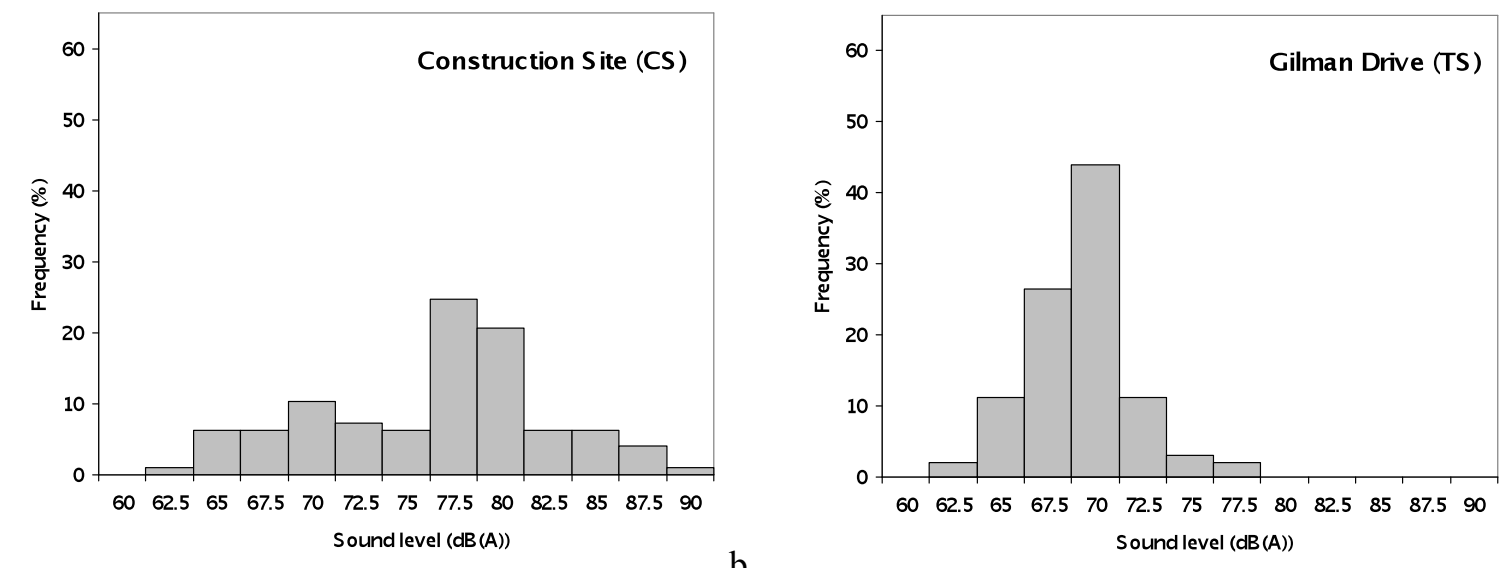

a. b.

Figure 2: Frequency distribution of the sound pressure levels $(\mathrm{dB}(\mathrm{A}))$ for the two sites during the surveys: (a) CS (b) TS.

\subsection{Air quality data}

Air quality varies significantly between the two sites. CS is clearly more burdened from an environmental point of view, as the PM count distribution has a long tail towards higher values (Fig. $3 \mathrm{a}, \mathrm{b}$ ). The minimum values are fairly similar for both sites (around $53 \mathrm{part} / \mathrm{l}$ ), but the maximum value is 3 times higher at CS (2868 part/l as opposed to $967 \mathrm{part} / 1$, or $80.3 \mu \mathrm{gm}^{-3}$ as opposed to $27.1 \mu \mathrm{gm}^{-3}$ ). The mean value is 4 times higher (806 part/l as opposed to $216 \mathrm{part} / 1$, or $22.6 \mu \mathrm{gm}^{-3}$ as opposed to 6.1 $\left.\mu \mathrm{gm}^{-3}\right)$. The measurements reflect the higher pollution load of the CS, which we attribute mainly to dust loading. However, given that the campus is an open area and well ventilated in an otherwise clean region, the absolute values are considered rather good.
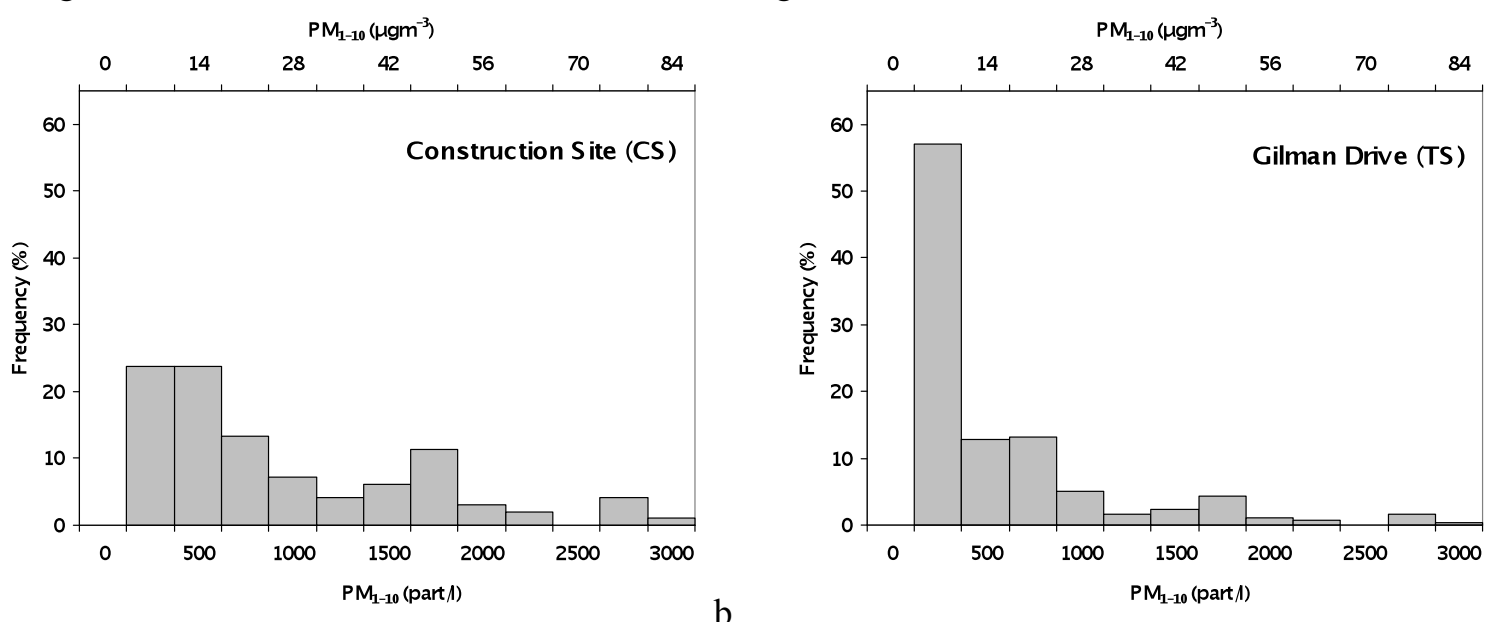

a.

b. 
Figure 3: Frequency distribution of the PM data for the two sites during the surveys (a) CS; (b) TS, in particles/litre and $\mu \mathrm{gm}^{-3}$ (estimated).

\subsection{Demographic data}

The majority of the interviews took place at TS (163 or $62.7 \%$ of the 260 , as opposed to 97 or $37.3 \%$ at the CS), as more people could be found there, given the nature of the site, an important public transportation hub for the campus.

Gender composition was predominantly males (63.3\%). Age is biased towards younger people with $67 \%$ in category $18-24$ and $19 \%$ in $25-34$. This is not surprising, given that both sites are on a University campus, where the majority of the population is students. Consistent with the general makeup of the student population at UCSD, Asians and Caucasians are about equally represented in the sample, at about $35 \%$ each. There were very few African or Mexican-Americans and Native Americans.

In terms of the activities carried out, about $80 \%$ of the people were either walking or standing, reflecting the nature of the sites. Only $20 \%$ were actually sitting. In agreement with the recorded activities 'waiting for the bus' is the main reason for being in the area $(39.4 \%$ out of the $62.7 \%$ that TS represents). The remaining group consists of people passing by on their way to home/work/class, etc. Every day users of the space are the largest group (47\%) followed by weekly users (35\%).

\section{Perception of environmental conditions}

\subsection{Thermal environment}

Regarding thermal sensation (Fig. 4), the conditions were perceived as warm (48.3\%). With regards to their overall comfort, $87.7 \%$ of the people voted comfortable. The interviewees seemed to prefer no change $(58.1 \%)$, or desired cooler conditions (39.2\%) and only $2.7 \%$ voted for warmer conditions. Regarding wind conditions, nearly $70 \%$ preferred no change with $22.3 \%$ asking for more wind.

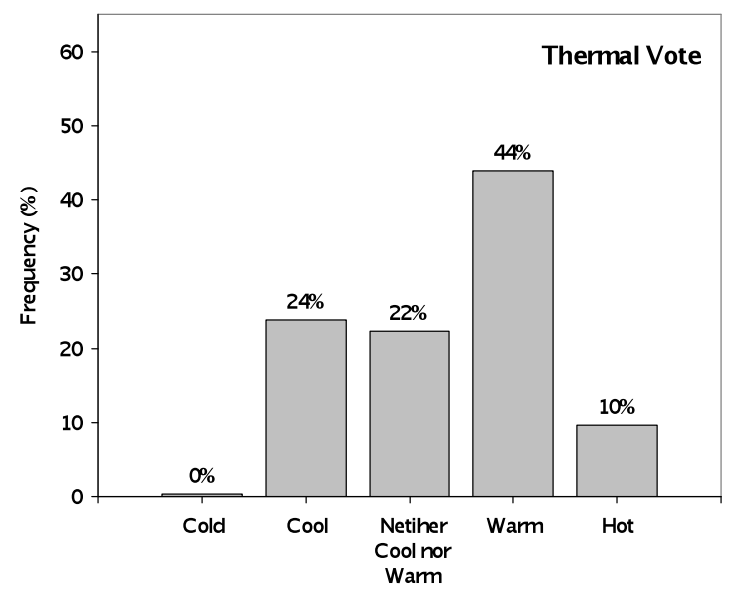

Figure 4: Frequency distribution of the thermal sensation during the surveys.

Wind perception is significantly correlated with wind preference $(\mathrm{r}=-0.28)$, air temperature $(\mathrm{r}=0.18)$ and wind speed $(\mathrm{r}=-0.19)$. Wind preference on the other hand is not correlated with wind speed but only with air temperature $(\mathrm{r}=-0.21)$. This is not surprising since under low wind speeds, as in these surveys, wind preference is influenced by thermal sensation $(r=-0.19)$.

Thermal vote is strongly correlated with thermal preference $(\mathrm{r}=-0.40)$, implying that respondents who felt warmer preferred to be cooler. Air temperature is well correlated with both thermal vote $(\mathrm{r}=0.33)$ and preference $(\mathrm{r}=-0.17)$, whereas humidity and wind speed are not. Finally thermal vote is correlated with solar radiation $(\mathrm{r}=0.13)$ but preference is not. These results are consistent with the RUROS field surveys (Nikolopoulou and Lykoudis, 2006).

Overall weather related comfort is only correlated with air temperature $(\mathrm{r}=0.16)$. Presumably, the limited variability of relative humidity and wind speed during the survey periods did not allow for any other relationships to manifest themselves. Also, no significant correlation exists between the comfort vote and sound or PM levels. 


\subsection{Acoustic environment}

The overall impression of the acoustic environment is that it is fairly noisy. In fact $56 \%$ voted for one of the noisy categories. Considering each site separately, it becomes clear that the CS is by far noisier than TS, with $81.3 \%$ of the votes on the noisy side of the scale, against $40.5 \%$. This is consistent with the sound pressure level profile of the two sites presented in Figure 2. Traffic and the construction are the major sources of annoyance. Considering each site separately, as expected, in the CS, construction is the single most dominant annoyance factor $(64 \%)$ followed by construction related activities, such as machinery, trucks, etc. In TS on the other hand, traffic is the only significant annoyance factor. Several interviewees did not consider any particular source being an annoyance.

The personal evaluation of the acoustic environment, correlates well with the recorded sound pressure levels $(r=0.54)$, as well as with the evaluation of how clean/dusty it feels $(r=0.47)$. The latter is presumably due to the common source of noise and pollution (vehicular traffic and construction activities), which also explains the good correlation between sound levels and PM levels $(\mathrm{r}=0.41)$.

\subsection{Air quality}

More than $50 \%$ of the participants consider the air to be very or fairly clean. A quarter of the people consider the air to be neither clean nor dusty and $22.3 \%$ fairly or very dusty (Fig. 5a). Examining the two sites separately, most people consider the air to be clean at TS $(67.5 \%)$ whereas, as expected, about $50 \%$ of the interviewees at the CS consider the air to be dusty (Table 2).
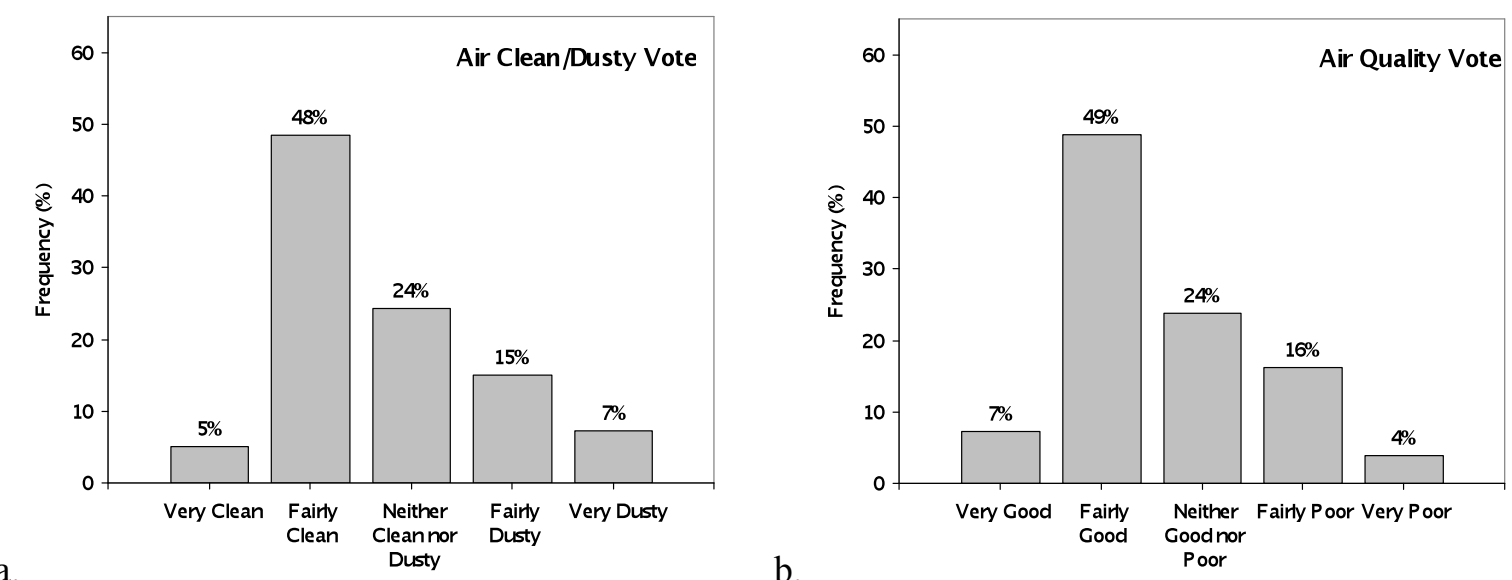

a.

Figure 5: Frequency distribution of (a) Air Clean/Dusty and (b) Air Quality votes

Table 2: Cumulative frequency distribution of Air Clean/Dusty and Air Quality votes for the two sites Air

\begin{tabular}{rcc} 
Clean/Dusty & CS & TS \\
\hline Very clean & 4.1 & 5.5 \\
Fairly clean & 25.8 & 62.0 \\
Neither clean & 20.6 & 6.4 \\
nor dusty & 33.0 & 4.3 \\
Fairly dusty & 16.5 & 1.8 \\
\hline Very dusty & 100.0 & 100.0 \\
\hline Total & 100
\end{tabular}

\begin{tabular}{rcc} 
Air Quality & CS & TS \\
\hline Very good & 6.2 & 8.0 \\
Fairly good & 26.8 & 62.0 \\
Neither good & 25.8 & 22.7 \\
nor poor & 32.0 & 6.7 \\
Fairly poor & 9.3 & 0.6 \\
Very poor & 100.0 & 100.0 \\
\hline Total & &
\end{tabular}

The air quality vote distribution (Fig. 5b) is practically identical to that of clean/dusty air vote, with similar complaints for the different sites (Table 2).

Air clean/dusty vote has a very good correlation with air quality vote $(\mathrm{r}=0.80)$. Both votes have good, statistically significant, correlations with PM count $(\mathrm{r}=0.31$ and 0.30$)$ and surprisingly with solar radiation $(\mathrm{r}=-0.31,-0.27)$. This could mean that the way people perceive PM related air quality is through the visual effect of particles, which becomes more noticeable under low irradiation conditions, resulting in negative Pearson correlation coefficients for solar radiation. This influence of visual clues of particulate matters, such as dust, affecting the evaluation of air quality and overall 
pollution is consistent with other studies, where visual evidence was the most important for the perception of pollution (Bickerstaff and Walker, 2001). In fact, the power of vision consistently has been found to be integral in helping people understand pollution, through the physical presence of dirt, soot, fumes, etc. (Bickerstaff, 2004; Hyslop, 2009).

Stacked bar-charts of the cumulative percentage of votes visualise the distribution of votes at different levels of PM (Fig. 6). Both Air Clean/Dusty and Air Quality votes demonstrate that as the PM increases, the number of 'clean' and 'good' votes decreases, whereas the number of 'dusty' and 'poor' votes increases. The bar on the far right of each graph, corresponding to 3000 particles/litre does not follow this trend. From the frequency distribution of the PM data (Fig. 3), it is apparent that there is little data for the high pollution loads and, therefore, the respective cumulative frequencies are not reliable.

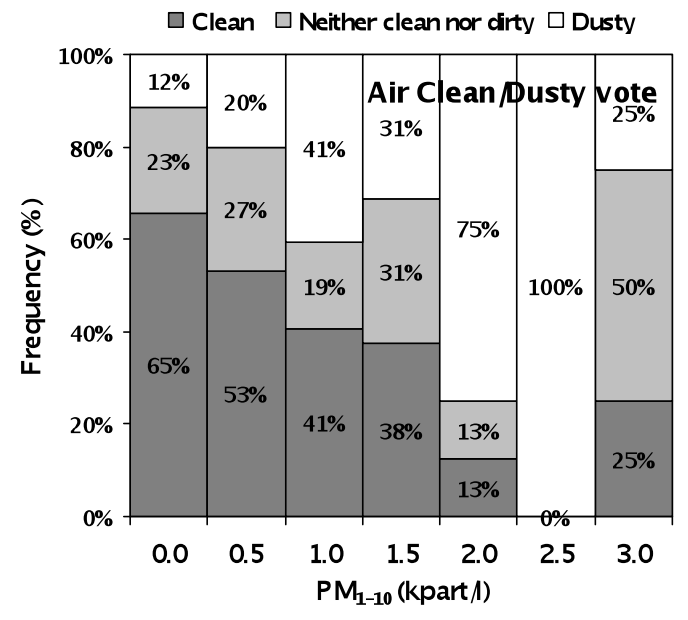

a.

Fig. 6: Frequency distributions for the votes of (a) Air Clean/Dusty and (b) Air Quality for different levels of PM $(\mathrm{N}=260)$.

\subsubsection{Perception of pollution and health problems}

In an attempt to understand the different stimuli that may affect people's evaluation of air quality, the possible history of medical conditions such as asthma, hay fever and eczema, as well as the smoking status were also investigated, as these could affect sensitivity to polluted air. The majority of the interviewees had no medical history of asthma, eczema, or hey fever. The most common condition was hay fever with $17.1 \%$ occurrence $(n=44)$, followed by asthma with $13 \%$ and eczema with less than $6 \%(n=15)$. Also, the majority of the people have never smoked $(79.9 \%)$, while $13.9 \%$ were former tobacco smokers.

To further examine whether there is a difference in the way people with medical or smoking history perceive air quality, i.e. whether they appear to be more sensitive to changes in PM levels we have created cross-tabulations of air quality vote vs. the existence or not of a medical history. This was done both for all the data and only for the CS data where, due to the elevated PM levels, we expect a clearer differentiation (Table 3 ).

Table 3: Cross tabulation of Air Quality votes vs hay fever history and smoking status.

\begin{tabular}{|c|c|c|c|c|c|c|c|c|c|c|}
\hline \multirow[b]{3}{*}{ Air Quality } & \multicolumn{4}{|c|}{ Hey Fever history } & \multicolumn{6}{|c|}{ Smoking status } \\
\hline & \multicolumn{2}{|c|}{ All Data } & \multicolumn{2}{|c|}{$\mathrm{CS}$} & \multicolumn{3}{|c|}{ All Data } & \multicolumn{3}{|c|}{$\mathrm{CS}$} \\
\hline & Yes & No & Yes & No & $\begin{array}{c}\text { Never } \\
\text { smoked }\end{array}$ & $\begin{array}{l}\text { Former } \\
\text { smoker }\end{array}$ & $\begin{array}{l}\text { Current } \\
\text { smoker }\end{array}$ & $\begin{array}{l}\text { Never } \\
\text { smoked }\end{array}$ & $\begin{array}{l}\text { Former } \\
\text { smoker }\end{array}$ & $\begin{array}{l}\text { Current } \\
\text { smoker }\end{array}$ \\
\hline Very good & 4.5 & 8.0 & 5.9 & 6.3 & 6.8 & 11.1 & 6.2 & 7.4 & & \\
\hline Fairly good & 40.9 & 50.2 & 17.6 & 29.1 & 47.8 & 55.6 & 43.8 & 24.7 & 44.4 & 28.6 \\
\hline $\begin{array}{l}\text { Neither good nor } \\
\text { poor }\end{array}$ & 29.5 & 23.0 & 17.6 & 27.8 & 22.7 & 19.4 & 50.0 & 22.2 & 22.2 & 71.4 \\
\hline Fairly poor & 20.5 & 15.5 & 47.1 & 29.1 & 18.8 & 8.3 & & 37.0 & 11.1 & \\
\hline Very poor & 4.5 & 3.3 & 11.8 & 7.6 & 3.9 & 5.6 & & 8.6 & 22.2 & \\
\hline
\end{tabular}




\begin{tabular}{|c|c|c|c|c|c|c|c|c|c|c|}
\hline \multirow[b]{3}{*}{ Air Quality } & \multicolumn{4}{|c|}{ Hey Fever history } & \multicolumn{6}{|c|}{ Smoking status } \\
\hline & \multicolumn{2}{|c|}{ All Data } & \multicolumn{2}{|c|}{$\mathrm{CS}$} & \multicolumn{3}{|c|}{ All Data } & \multicolumn{3}{|c|}{$\mathrm{CS}$} \\
\hline & Yes & No & Yes & No & $\begin{array}{c}\text { Never } \\
\text { smoked }\end{array}$ & $\begin{array}{l}\text { Former } \\
\text { smoker }\end{array}$ & $\begin{array}{l}\text { Current } \\
\text { smoker }\end{array}$ & $\begin{array}{c}\text { Never } \\
\text { smoked }\end{array}$ & $\begin{array}{l}\text { Former } \\
\text { smoker }\end{array}$ & $\begin{array}{l}\text { Current } \\
\text { smoker }\end{array}$ \\
\hline Very good & 4.5 & 8.0 & 5.9 & 6.3 & 6.8 & 11.1 & 6.2 & 7.4 & & \\
\hline Fairly good & 40.9 & 50.2 & 17.6 & 29.1 & 47.8 & 55.6 & 43.8 & 24.7 & 44.4 & 28.6 \\
\hline $\begin{array}{l}\text { Neither good nor } \\
\text { poor }\end{array}$ & 29.5 & 23.0 & 17.6 & 27.8 & 22.7 & 19.4 & 50.0 & 22.2 & 22.2 & 71.4 \\
\hline Fairly poor & 20.5 & 15.5 & 47.1 & 29.1 & 18.8 & 8.3 & & 37.0 & 11.1 & \\
\hline Very poor & 4.5 & 3.3 & 11.8 & 7.6 & 3.9 & 5.6 & & 8.6 & 22.2 & \\
\hline Total & 100.0 & 100.0 & 100.0 & 100.0 & 100.0 & 100.0 & 100.0 & 100.0 & 100.0 & 100.0 \\
\hline
\end{tabular}

It appears that only people with a medical history of hay fever voted more frequently for poor air quality conditions than those without (Table 3 ). In fact of those with hay fever, $25.0 \%$ overall and nearly $58.9 \%$ in the CS voted for poor air quality, compared to $18.8 \%$ and $36.7 \%$ of those without hay fever.

People with asthma or eczema history voted less frequently for poor air quality conditions than those without this medical history, which could be attributed to the small number of interviewees we had with a history of asthma and eczema, hence rendering such an analysis unreliable.

Current smokers seem to be the least sensitive to air quality (Table 3) since they invariably voted for neutral or good conditions, whereas $22.7 \%$ of the non-smokers voted for poor conditions in both sites, and $45.6 \%$ when only the CS was considered. The values for former smokers were $13.9 \%$ and $33.3 \%$, respectively.

\subsubsection{Perception of pollution and health symptoms}

People were also asked whether they had any symptoms such as blocked or dry nose, dry throat/ mouth or skin, as well as dry/ itchy eyes, and were asked to evaluate these on a 5-point scale varying from 'not at all' to 'very severe'. Such symptoms were to be evaluated against sensitivity to air quality to investigate the means by which pollutants are being perceived (e.g. sensory irritation to eyes, nose, throat, etc.).

Most of the interviewees (around 70\%) did not present any symptoms related to poor air quality, while a $20-25 \%$ presented some mild symptoms. The distribution of the symptoms is the same for both sites and does not depend on gender (not shown).

In order to explore the possible relationships between medical history and smoking status with various symptoms and perception of air quality, a series of partial correlation and chi-square analyses were carried out. There appears to be a tendency for smoking to make individuals less sensitive to poor air quality, but given the small number of interviewees it was only significant at the 0.08 level. With the constraint of having small samples in the various medical history categories, there is no indication that prior medical history plays a role in the way people perceive air quality.

Mann-Whitney (for medical history) and Kruskal-Wallis (for smoking status) tests, conducted for equality of location of the respective observed statistical distributions, also indicated that there is no differentiation of the PM-related sensitivity according to the existence or not of a medical history.

Chi-square tests of the observed dichotomous (trichotomous) responses for medical history (smoking status) against equiprobability, per symptom reported, revealed that medical history may affect the rate of occurrence of a specific symptom. A history of hay fever increases the odds of developing a mild symptom of Blocked Nose ( $48 \%$ observed versus the $24 \%$ expected, significant at $\mathrm{p}<0.01)$, Dry Nose $(30 \%$ observed versus the $18 \%$ expected, $\mathrm{p}<0.05)$ and Dry Mouth $(33 \%$ observed versus the $19 \%$ expected, $\mathrm{p}<0.05)$. Also a history of eczema is associated with increased moderate skin dryness $(27 \%$ observed versus the $9 \%$ expected, $\mathrm{p}<0.05)$. Finally Asthma is related to increased mild Dry Mouth (35\% observed versus the $19 \%$ expected, $\mathrm{p}<0.05)$ and moderate Dry Throat symptoms $(12 \%$ observed versus the $4 \%$ expected, $\mathrm{p}<0.05)$. 
Smoking is associated with increased mild symptoms of Dry Nose, and mild and moderate Dry Throat (both for current and former smokers, Table 4). Current smokers also report increased symptoms of eye dryness, although this is only based on 10 responses.

Table 4: Chi-square analysis for smoking history and prevalence of different symptoms

\begin{tabular}{|c|c|c|c|c|c|c|c|}
\hline & \multirow[b]{2}{*}{$\begin{array}{l}\text { Symptom } \\
\text { Severity }\end{array}$} & \multicolumn{2}{|c|}{ Dry Nose * } & \multicolumn{2}{|c|}{ Dry Throat* } & \multicolumn{2}{|c|}{ Dry / Itchy Eyes ** } \\
\hline & & $\begin{array}{c}\text { Observed } \\
(\%)\end{array}$ & $\begin{array}{c}\text { Expected } \\
(\%)\end{array}$ & $\begin{array}{c}\text { Observed } \\
(\%)\end{array}$ & $\begin{array}{c}\text { Expected } \\
(\%)\end{array}$ & $\begin{array}{c}\text { Observed } \\
(\%)\end{array}$ & $\begin{array}{c}\text { Expected } \\
(\%)\end{array}$ \\
\hline Never smoked & A little & 14 & 17 & 14 & 18 & & \\
\hline Former smoker & & 33 & 17 & 33 & 18 & & \\
\hline Current smoker & & 25 & 17 & 31 & 18 & & \\
\hline Never smoked & Moderate & & & 2 & 4 & & \\
\hline Former smoker & & & & 11 & 4 & & \\
\hline Current smoker & & & & 13 & 4 & & \\
\hline Never smoked & Quite a bit & & & & & 2 & 4 \\
\hline Former smoker & & & & & & 3 & 4 \\
\hline Current smoker & & & & & & 31 & 4 \\
\hline
\end{tabular}

${ }^{*} \mathrm{p}<0.05, * * \mathrm{p}<0.001(\mathrm{~N}=260)$.

\section{$5 \quad$ Modelling exposure-response relationships}

An attempt was made to build models for the prediction of the various perception votes, using meteorological, noise and PM measurements, as well as factors like gender, ethnic group, age, medical and smoking history as independent variables and controlling factors. We focused on the perception of air quality, which is the key parameter investigated in this paper. This exercise should provide information on the significance of the independent variables and factors with regard to the human perception and response to air quality.

The main parameters of interest in this study, namely the votes, are ordinal. That means that they are ordered into classes, yet the distances between adjacent classes are unknown, and by no means equal to each other. Even though ordinal parameters can be used in the context of an ordinary regression procedure this would imply an underlying assumption of equality of distances between the categories and the result would be a continuous instead of an ordinal variable.

In order to avoid these shortcomings we employed an appropriate regression analysis based on ordinal regression, using SPSS (SPSS Inc, 2008). Ordinal regression, instead of providing an estimate of the dependent parameter, provides an estimate of the probability that the dependent parameter will fall into each ordinal category. The category corresponding to the maximum probability is the final estimate for the dependent variable. The background theory for this approach is given in the Appendix.

Using the parallel line test, we found that the assumptions underlying ordinal regression are fulfilled and can be used to predict air quality and cleanness vote using PM count (Table 5). Other environmental and personal factors such as solar radiation, medical or smoking history, etc. have been tested but do not produce models with significant coefficients, and so they have been excluded from further discussion.

Table 5: Ordinal model estimates for prediction of Air Quality votes $(\mathrm{N}=260)$

\begin{tabular}{|c|c|c|c|c|c|}
\hline & $\begin{array}{l}\text { AirQuality } \\
\text { Vote }\end{array}$ & & Estimate & Std. Error & Sig. \\
\hline \multirow[t]{4}{*}{ Threshold } & Very good & $=1$ & -2.22 & .25 & .000 \\
\hline & Fairly good & $=2$ & .68 & .16 & .000 \\
\hline & $\begin{array}{l}\text { Neither good } \\
\text { nor poor }\end{array}$ & $=3$ & 1.90 & .20 & .000 \\
\hline & Fairly poor & $=4$ & 3.82 & .36 & .000 \\
\hline Location & PM & & .001 & .000 & .000 \\
\hline
\end{tabular}


The cross-tabulation of the results (Table 6) demonstrates that the Air Clean/Dusty model that uses only PM count as an independent variable is reproducing the recorded votes fairly well - about $50 \%$ correct classifications for the 3 middle categories (i.e. $2=$ fairly clean, $3=$ neither clean nor dusty, $4=$ fairly dusty), and $20 \%$ for the high category ( $5=$ very dusty, Gamma statistic $=0.545, \mathrm{p}=0.000$ ).

Table 6: Reproduction (\%) of the Air Clean/Dusty vote by the ordinal regression model ( $\mathrm{N}=260)$

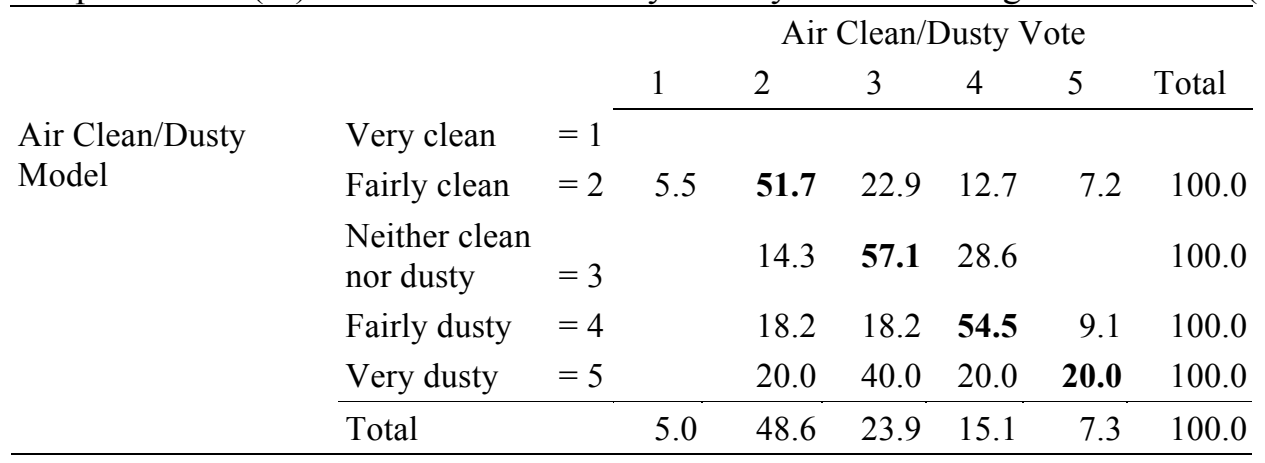

Air Quality vote can also be estimated by PM count (Table 5) and the parallel line test was also successful. However, cross-tabulation of the model predictions with the actual interview votes shows that the model classifies all cases into only two out of five classes. Hence it cannot be considered as successful even though the Gamma statistic $(0.540, \mathrm{p}<0.01)$ is satisfactory. As before, other factors such as medical or smoking history, etc. have been tested but do not produce models with significant parameters.

Further insight on the probability of having a certain response under specific conditions values of the independent (control), parameter can be obtained by the cumulative probability plots (Fig. 7), generated by introducing the ordinal regression model parameters (See eq. 3 in the Appendix).

Hence, to predict how different people would perceive the air cleanness or quality at different PM concentrations we can look at the cumulative distributions presented in Figures $7 \mathrm{a}$ and $7 \mathrm{~b}$ respectively. For example, at 3200 particles/litre (or around $90 \mu \mathrm{g} / \mathrm{m}^{3}$ ), $50 \%$ of the population would be expected to vote higher than 4 , i.e. very dusty (Fig. 7a) and the air quality would be perceived as very poor for about $32 \%$ of the population (Fig. $7 \mathrm{~b}$ ).
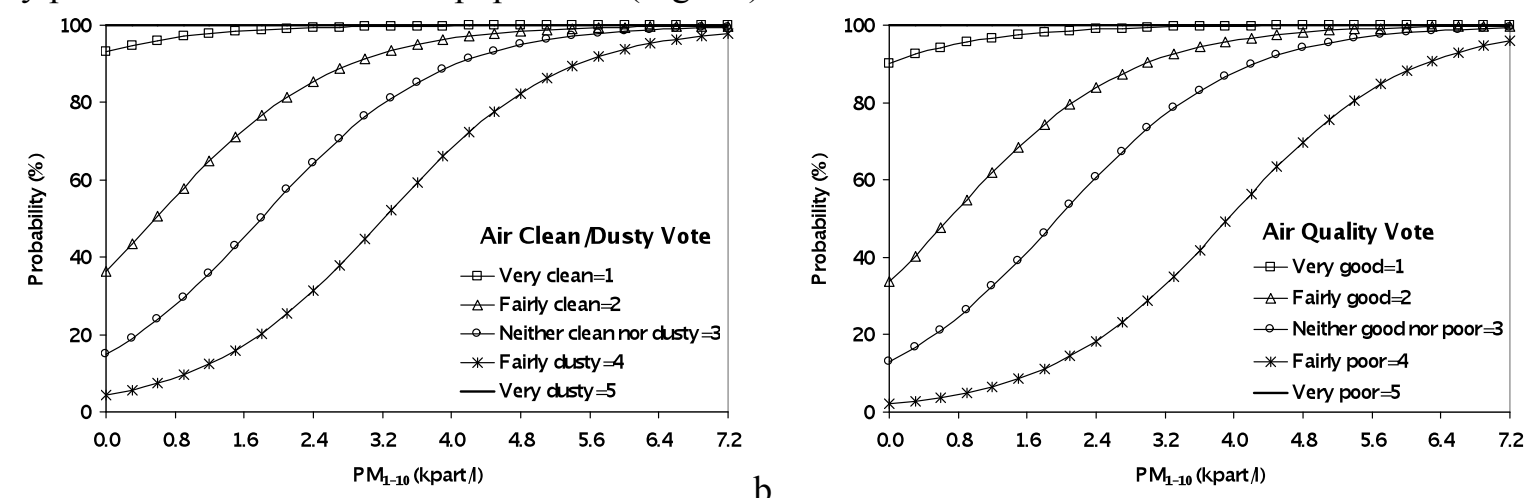

Figure 7: Cumulative response for PM and the proportion of the population that expresses different votes of (a) Air Cleanness and (b) Air Quality ( $N=260)$.

The concentrations at which poor air quality is perceived by a majority of the population might seem high compared to the current EU limits of $40 \mu \mathrm{g} \mathrm{m}^{-3}$ (Commission of the European Communities, 2001), but it should be borne in mind that the EU limits refer to a mean annual value, whereas our analysis has been performed on instantaneous exposures. Instantaneous exposures will be significantly larger, especially in proximity to roadways and during high pollution episodes, and could be avoided based on individual perception. 


\section{Conclusions}

We have presented the results of a localised study aimed at enhancing our understanding of the connections between individual perception and exposure to different environmental stimuli; microclimate, noise and especially particulate matter. People were asked to evaluate environmental quality at the same time and location as highly time-resolved physical measurements were carried out, so the objective and subjective parameters could be directly linked. Since our sample size is relatively small (260 interviews), the results should be regarded as indicative of the trends in actual perception of pollution and the relative importance of various other factors.

The surveys took place in daytime on sidewalks next to a road construction site (CS) and a medium density traffic site (TS). The meteorological conditions were generally sunny, warm, moderately humid, and with light winds. At both sites the environment was noisy. The particulate matter concentration was generally low, but the CS was burdened with higher PM counts (presumably from dust) and higher sound levels.

The overall comfort was determined primarily by the thermal environment, with no correlation between comfort and sound or PM levels. Overall air quality is considered to be clean by more than $50 \%$ of the participants. Air quality vote distribution is strongly correlated to the Air Clean/Dusty votes, and both of these perception votes are correlated with the PM count. Overall as the concentration of PM increases the number of 'clean air' and 'good air quality' votes decreases, whereas the number of 'dusty air' and 'poor air quality' votes increases. Through the exposureresponse relationships between the various perception votes and PM, it was possible to predict air cleanness using the PM count. The model performed fairly well for the three middle categories, where the majority of the votes existed and less well for the two extreme categories.

Surprisingly, these perception votes also present a significant negative correlation with solar radiation, suggesting that the way people perceive PM is through the visual effect of particles that inevitably becomes more noticeable under low irradiation conditions. Hyslop (2009) suggests that impaired visibility is the result of air pollution due to light scattering on particles or more extreme cues such as smoke from chimneys or car motor exhausts.

The effect of medical or smoking history on the perceived air quality was also evaluated. People with a medical history of hay fever voted more frequently for poor air quality conditions than those without, whereas current smokers were the least sensitive to air quality. Medical history affects the occurrence of specific symptoms as can be expected, e.g. symptoms of blocked nose for those suffering of hay fever, dry throat for smokers. The analysis also suggests that there appears to be no statistically significant differentiation of the PM-related sensitivity according to the existing medical history - although the sample with such history is small.

This work shows promising results but the confidence of these results is affected by the small number of responses. An extensive study investigating different levels of air pollution in different urban settings would help us to disentangle the effect of these parameters. Furthermore, it would help us to identify threshold levels that different air pollutants need to reach for them to be perceived by individuals, while investigating the means by which these pollutants are being perceived (e.g. sensory irritation to eyes, nose, throat; visual appearance, etc.).

Understanding the role of air quality in the overall satisfaction with the environment will open new dimensions for urban planning and the development of urban spaces. Individuals' perception of ambient environmental conditions, in particular microclimate, noise and air quality, can influence the 'liveability' of a city. An in-depth analysis of the human parameter will open new horizons for evaluating the use of physical intervention through urban and built form in urban design to improve environmental quality and increase adaptive capacity to climate change. The impact on urban design, in relation to the allocation of uses and activities in the urban context could also be significant. Finally, it can indirectly inform air quality management schemes and outreach campaigns by addressing the public's interaction with the environment and motivation for change, to induce environmentally sustainable behaviour. As Uzzell and Moser (2006) highlight "it is not the quality of the environment, but how people interact with it that may be a principal explanatory factor in wellbeing". 


\section{Acknowledgements}

This project was funded by the SETsquared UK/US Sustainable Environment Collaborative Programme, from the Science Bridges Initiative.

As this work has spanned across different disciplines, we are grateful to those that sent us questionnaires they have used in the indoor environment and other interesting literature. More specifically, we would like to thank Prof. Peder Wolkoff from the National Research Centre for the Working Environment in Denmark; Dr Karin Engvall from the Stockholm Office of Research and Statistics in Sweden; Prof. Pawel Wargocki from the International Centre for Indoor Environment and Energy at Technical University of Denmark; Prof. David Uzzell from the Dept. of Psychology, University of Surrey (UK); and Dr Mark J. Mendell from the Indoor Environment Department, Lawrence Berkeley National Laboratory (USA).

Finally, special thanks are due to all the UCSD students who carried out the field surveys (Anthony Dominguez, Mandana Farhadieh, Anders Nottrott, Hared Ochoa) and Mr Faisal Aljawabra at the University of Bath for his help in digitizing the interview data.

\section{Appendix}

Ordinal logistic regression is a procedure aiming to predict the odds of observing a particular score or less (Agresti, 2002; SPSS Inc, 2008). In the case of votes based on sensation this could be formulated as modeling the following odds:

$$
\boldsymbol{U}_{j}=\boldsymbol{P}(\boldsymbol{Y} \leq \boldsymbol{J}) / \boldsymbol{P}(Y>\boldsymbol{J})
$$

where $P$ denotes probability, $Y$ is the response variable and $j=1, n-1$ where $\mathrm{n}$ is number of classes. Class $n$ does not have an odds associated to it since the range below or equal to this class covers the whole data set.

The ordinal logistic model for a vector of independent variables and controlling factors $X_{i}$, is then:

$$
\operatorname{In}\left(U_{j}\right)=a_{j}+\sum_{i}-b_{i} \cdot X_{i}
$$

Larger $b_{i}$ location coefficients indicate an association with higher votes. A positive coefficient for a dichotomous factor implies that higher votes are more likely for the first category. A negative coefficient implies lower votes are more likely. For a continuous variable, a positive coefficient implies that as the values of the variable increase, the likelihood of larger votes increases.

Each logit $\left(U_{j}\right)$ has its own threshold, $a_{j}$ but the same location $b_{i}$ for each parameter of the control vector $X_{i}$. That means that the effect of the independent variable is the same for the different logit functions. This suggests that the results are a set of parallel lines or planes-one for each category of the outcome variable, in our case for each vote. This assumption can be checked by allowing the coefficients to vary, estimating them, and then testing whether they are all equal.

For a single control (independent) variable, $X$, if the assumption of parallel lines is valid, the probability of a response $Y$ being greater or equal than $j$, when the independent variable has the value $x$ is:

$$
P(Y \geq \mid X=x)=1-\frac{e^{a_{j}-b x}}{1+e^{a_{j}-b x}}
$$

A good model has statistically significant location $b_{i}$ and a favourable test of parallel lines (large significance level). This is an initial assessment though. The performance of the model in terms of assigning the cases to the correct ordinal class has to be assessed in a second step. To do that we employ the Gamma statistic on the crosstab table among the original and the modelled classifications. Gamma statistic is a symmetric measure of association between two ordinal variables that ranges between -1 and 1 . Values close to an absolute value of 1 indicate a strong relationship between the two variables. 


\section{References}

Agresti, A. (2002). Categorical Data Analysis, 2nd rev-ed., New York: John, Wiley \& Sons.

Amudsen, A.H., Klæboe, R. and Fyhri, A. (2008). Annoyance from vehicular air pollution: Exposureresponse relationships for Norway, Atmospheric Environment, 42, 7679-7688.

Badland, H.M. and Duncan, M.J. (2009). Perceptions of air pollution during the work-related commute by adults in Queensland, Australia, Atmospheric Environment, 43, 5791-5795.

Bickerstaff,, K. (2004). Risk perception research: socio-cultural perspectives on the public experience of air pollution, Environment International, 30, 827-840.

Bickerstaff, K. and Walker, G. (2001). Public understandings of air pollution: the 'localisation' of environmental risk, Global Environmental Change, 11, 2, 133-145.

Bonnes M., Uzzell, D., Carrus, G. and Kelay, T. (2007). Inhabitants' and experts' assessments of environmental quality for urban sustainability, Journal of Social Issues, 63, 1, 59-78.

Brody, S.D., Peck, B.M. and Highfield, W.E. (2004). Examining localized patterns of air quality perception in Texas: a spatial and statistical analysis, Risk Analysis, 24(6), 1561-1574..

Centre for Renewable Energy Sources (2002). RUROS home page - Objectives and methodology, http://alpha.cres.gr/ruros/quest en.pdf. Accessed March 2009.

Commission of the European Communities (2001). Commission Directive of 17 October 2001 amending Annex V to Council Directive 1999/30/EC relating to limit values for sulfur dioxide, nitrogen dioxide and oxides of nitrogen, particulate matter and lead in ambient air. Official Journal of the EC, L 278/35.

County of San Diego Air Pollution Control District (2007). Five Year Air Quality Data Summary available online at http://www.sdapcd.org/air/reports/smog.pdf. Accessed March 2009.

Craik, K.H. and Zube, E.H. (1976). Perceiving Environmental Quality: Research and Applications, Plenum Press, New York.

Day, R. (2007). Place and the experience of air quality, Health \& Place, Vol. 13, pp. 249-260.

Daniels, M. J., F. Dominici, J.M. Samet and S.L. Zeger (2000). Estimating particulate matter-mortality dose-response curves and threshold levels: An analysis of daily time-series for the 20 largest US cities, American Journal of Epidemiology, 152, 5, 397-406.

Dominguez, A., Kleissl, J., Farhadi, M., Kim, D., Liu, W., Mao, Y., Nguyen, H.T., Roshandell, M., Sankur, M., Shiga, Y., Linden, P. and Hodgkiss, W. (2007). Decision-Making Using Real-Time Observations for Environmental Sustainability, American Geophysical Union Fall Meeting 2007, Poster H13A-0972.

Engvall, K., Norrby, C. and Sandstedt, E. (2004). The Stockholm Indoor Environment Questionnaire: a sociologically based tool for the assessment of indoor environment and health in dwellings, Indoor Air, 14, 1, 24-33.

Environment Protection Agency (2003). A Standardised EPA Protocol for Characterizing Indoor Air Quality in Large Office Buildings, USA.

Fang L., Wyon, D.P., Clausen, G. and Fanger, P.O. (2004). Impact of indoor air temperature and humidity in an office on perceived air quality, SBS symptoms and performance. Indoor Air Suppl.; 14, 7, 74-81.

Harrison, R.M. (2004). Key pollutants - airborne particles, Science of the Total Environment, 334-335, 3-8.

Howel D., Moffatt, S., Bush, J., Dunn, C.E. and Prince, H. (2003). Public views on the link between air pollution and health in Northeast England, Environmental Research, 91, 3, 163-171.

Hyslop, N.J. (2009). Impaired visibility: the air pollution people see, Atmospheric Environment, 43, 1, $182-195$

Kang, J. and Zhang, M. (2010). Semantic differential analysis of the soundscape in urban open public spaces, Building and Environment, 45, 150-157.

Kaur, S., Nieuwenhuijsen, M.J. and Colvile, R.N. (2005). Pedestrian exposure to air pollution along a major road in Central London, UK, Atmospheric Environment, 39, 7307-7320 
Klæboe, R., Amudsen, A.H. and Fyhri, A. (2008). Annoyance from vehicular air pollution: A comparison of European exposure-response relationships, Atmospheric Environment, 42, 76897694.

Llop, S., Ballester, F., Estarlich, M., Esplugues, A., Fernandez-Patier, R., Ramon, R., Marco, A., Aguirre, A., Sunyer, J. and Iniguez, C. (2008). Ambient air pollution and annoyance responses from pregnant women, Atmospheric Environment, 42, 2982-2992.

Mendell, M.J., Mirer, A. and Lei-Gomez, Q. (2007). Contaminants in Buildings and Occupied Spaces as Risk Factors for Occupant Symptoms in U.S. Office Buildings: Findings from the U.S. EPA BASE Study, LBNL-63370.

Moffet, R.C., Desyaterik, Y., Hopkins, R.J., Tivanski, A.V., Gilles , M.K., Wang, Y., Shutthanandan, V., Molina, L.T., Abraham, R.G., Johnson, K.S., Mugica, V., Molina, M.J., Laskin, A. and Prather, K.A. (2008) Characterization of aerosols containing $\mathrm{Zn}, \mathrm{Pb}$, and $\mathrm{Cl}$ from an industrial region of Mexico City, Environmental Science \& Technology, 42, 19, 7091-7097.

Nikolopoulou, M, Baker, N. and Steemers, K. (2001). Thermal comfort in outdoor urban spaces: the human parameter, Solar Energy, 70, 3, 227-235.

Nikolopoulou, M., Lykoudis, S. and Kikira, M. (2004). Thermal comfort models for open urban spaces, Designing Open Spaces in the Urban Environment: a Bioclimatic Approach, Centre for Renewable Energy Sources, EU FP5.

Nikolopoulou, M. and Lykoudis, S. (2006). Thermal comfort in outdoor urban spaces: analysis across different European countries, Building and Environment, 41, 11, 1455-1470.

Oglesby, L., Kunzli, N., Monn, C., Schindler, C., Ckermann-Liebrich, U. and Leuenberger, P. (2000). Validity of annoyance scores for estimation of long-term air pollution exposure in epidemiologic studies: the Swiss Study on Air Pollution and Lung Diseases in Adults (SAPALDIA). American Journal of Epidemiology, 152, 75-83.

Park, S.S., Kleissl, J., Harrison, D., Nair, N.P., Kumar, V. and Ondov, J. (2006). Investigation of $\mathrm{PM}_{2.5}$ episodes using semi-continuous instruments at the Baltimore Supersite, Aerosol Sci. Tech., 40, $10,845-860$.

Pfafflin J.R. \& Ziegler E.N. (Eds) (2006). Encyclopedia of Environmental Science and Engineering, Fifth Edition, v. II, CRC Press, Taylor \& Francis, London.

Rotko, T., Oglesbyb, L., Künzli, N., Carrer, P., Nieuwenhuijsen, M.J. and Jantunen, M. (2002) Determinants of perceived air pollution annoyance and association between annoyance scores and air pollution (PM2.5, NO2) concentrations in the European EXPOLIS study, Atmospheric Environment, 36, 4593-4602.

Sapkota, A., Symons, J.M., Kleissl, J., Wang, L., Parlange, M.B., Ondov, J., Eggleston, P.A. and Buckley, T.J. (2005). Impact of the 2002 Canadian forest fires on particulate matter air quality in Baltimore City, Environmental Science and Technology, 39, 1, 24-32.

Sarrat, C., Lemonsu, A., Masson,V., and Guedalia,D. (2006). Impact of urban heat island on regional atmospheric pollution, Atmospheric Environment, 40, 1743-1758.

Seinfeld, J. and Pandis, S. (1997). Atmospheric Chemistry and Physics: From Air Pollution to Climate Change, Wiley-Interscience.

Semenza, J.C., Wilson, D.J., Parra, J., Bontempo, B.D., Hart, M., Sailor, D.J. and George, L.A. (2008). Public perception and behaviour change in relationship to hot weather and air pollution, Environmental Research, Vol. 107, 401-411.

Szeremeta, B., Henrique, P. and Zannin, T. (2009). Analysis and evaluation of soundscapes in public parks through interviews and measurement of noise, Science of the Total Environment , 407, 6143-6149.

Toner, S.M., Shields, L.G., Sodeman, D.A. and Prather, K.A. (2008). Using mass spectral source signatures to apportion exhaust particles from gasoline and diesel powered vehicles in a freeway study using UF-ATOFMS, Atmospheric Environment, 42, 3, 568-581.

SPSS. Inc. (2008). Ordinal Regression. http://www.norusis.com/pdf/ASPC v13.pdf. Accessed Nov. 2008. 
Uzzell, D. and Moser G. (2006). Environment and quality of life, European Review of Applied Psychology, 56, 1, 1-4.

Wargocki, P. (2004). Sensory pollution in buildings, Indoor Air, 14 (Suppl. 7), 82-91.

Wargocki, P., Wyon, D.P., Baik, Y.K., Clausen, G. and Fanger, P.O. (1999). Perceived air quality, Sick Building Syndrome (SBS) symptoms and productivity in an office with two different pollution loads, Indoor Air, 9, 165-179.

Western Regional Climate Center (2009). NCDC 1971-2000 Monthly Normals San Diego WSO Airport, California, http://www.wrcc.dri.edu/cgi-bin/cliNORMNCDC2000.pl?ca7740. Accessed March 2009.

Yaghoobian, N., Kleissl, J. and Krayenhoff, S. (2010). Modeling the thermal effects of artificial turf on the urban environment, Journal of Applied Meteorology and Climatology, Vol. 49, 3, 332345 .

Yang, W. and Kang, J. (2005). Acoustic comfort evaluation in urban open public spaces. Applied Acoustics, 66, 211-229. 